\title{
Portability of the Job Involvement and Job Satisfaction Constructs between the United States of America and South Africa
}

\author{
A B Boshoff and C Hoole \\ Graduate School of Management, University of Pretoria
}

\begin{abstract}
The notion of portability of constructs measured by psychometric instruments is introduced. Psychometric investigations by means of Principal Components Analyses, Item Analyses and calculation of Cronbach Alpha on the items of two generally used instruments are described. The results indicate that the constructs measured by the Kanungo Job Involvement Questionnaire and the Minnesota Satisfaction Questionnaire as well as the instruments themselves seem to be robust as far as portability between the Unites States of America and South Africa is concemed.
\end{abstract}

\section{INTRODUCTION}

The notion of portability of constructs used in a psychometric measure is mentioned in several publications (Stimpson, Robinson, Waronusuntikule \& Zheng, 1990; Stimpson, Huefner, Narayanan \& Shanthaleamar, 1992). The problem seems to be that instruments developed in one country to measure specific constructs are sometimes psychometrically unacceptable when used in a different country on people of a different culture. This makes comparison of levels of a construct in different countries very difficult. Relationships among constructs e.g. attitudes and success as an entrepreneur (Robinson, Stimpson, Huefner \& Hunt (1991)) can often not be cross validated across countries due to the non-availability of measuring instruments which have been proved to be valid and reliable when used on samples from different countries. Essentially the problem seems to be that 
the interpretations given to especially questionnaire items tend to differ in different cultures, even among individuals speaking the same language.

Whether portability existed with regard to two measures widely used in research on and in organizations is the question investigated in the present study. The rationale was that if non-ponability was a problem in entrepreneurship research it could also confound research findings in other fields. Kerlinger (1986) states that confusion about the contents of a construct is one of the most fundamental problems in social research. Some more clarity on whether the constructs embodied in the Job Involvement Inventory (Kanungo, 1982) and the Minnesota Satisfaction Questionnaire (Weiss, Dawis, England \& Lofquist, 1967), both widely used instruments, would be stable when used on a South African rather than United States of American sample was therefore sought..

The purpose of the present paper is therefore to examine the portability of the constructs, measured by two instruments developed in the United States of America, to the South African situation. This meant that some psychometric investigation of these measuring instruments had to be undertaken. The aim is not to give final answers about the factor structures and contents of the constructs embodied in the instruments but rather to provide some clarity on how well the constructs stood up to psychometric evaluation when used in South Africa in contrast to the United States of America.

\section{METHOD}

\section{Measuring instruments}

The first instrument which was included in the present study is the Job Involvement Questionnaire developed by Kanungo (1982). This instrument was developed as an improvement on the up to then extensively used job involvement measure of Lodahl and Kejner (1965). The scale is supposed to measure job involvement unidimensionally as psychological identification with one's work. Kanungo (1982) reported the reliability of the instrument as Alpha $=0.83$. The instrument consists of 10 items to which respondents have to react on a 10-point scale.

The second instrument which was subjected to investigation is the Minnesota Satisfaction (1yestionnaire (Weiss, Davis, England \& Lofquist, 1967). It was completed by the same respondents who completed the Kanungo Job Involvement Questionnaire. The MSQ is supposed to measure job satisfaction in terms of two dimensions i.e. intrinsic and extrinsic job satisfaction, each measured 
by means of 10 items. Responses are given on a five point Likert-type scale. Job satisfaction is seen as the result of a psychological comparison process involving the appraisal of current job experiences against personal standards of comparison, with the implication that both negative and positive discrepancies may arise, resulting in various degrees of job satisfaction (or dissatisfaction).

\section{Procedure}

Data on the two instruments were gathered during a research project of which the main aims were different from that of this paper.

The Job Involvement Questionnaire and the Minnesota Satisfaction Questionnaire were administered during a study in which information on the Career Orientations, Job Satisfaction, Job lnvolvement and Biographic and work situation backgrounds of professional people and the relationships among these variables were gathered. The data was gathered by means of a mail survey of randomly selected samples of the South African members of 14 professions. More information on the procedures followed and the composition of the samples can be found in Boshoff, Bennett and Kellerman (1994).

\section{RESULTS}

The responses of 1791 professional individuals engaged in 14 different professions on the two instruments i.e. Kanungo Job Involvement Inventory and the Minnesota Satisfaction Questionnaire were analyzed in the present study. A preliminary analysis was also reported by Boshoff, Kaplan, Schutte \& Kellemnan (1989).

In the case of the Kanungo instrument the responses of the Sample $(\mathrm{N}=1$ 791) were firstly analyzed for Principal Components. A one-factor solution was firstly specified and the Promax rotation technique was used. Eigenvalues between 4.06 and .40 were obtained, with two eigenvalues (4.06 and 1.14) being $>1$. All ten items loaded $>.30$ on the one factor with loadings varying between .34 and .76 . Eight of the 10 items loaded $>.50$ on this factor.

Item analysis (calculation of corrected $\mathrm{ru}_{\mathrm{u}}$-values of the items) was then carried out. This analysis indicated that, with the exception of one item, the $\mathrm{rtu}$ values exceeded .30 . This item had a $\mathrm{r}_{\mathrm{rt}}$-value of .28 and it was felt that it should probably not be included in the measure if a one-factor solution was to be accepted. 
Cronbach's Coefficient Alpha was used as a measure of internal consistency and resulted in a alpha value of .83 . The Cronbach Alpha results confirmed the Item analyses results by indicating that the removal of the same item i.e. item 7 in the Job Involvement Questionnaire, would maximize the value of Cronbach's Alpha.

The suspicious item was left out of further analysis and the three sets of analyses were repeated on the remaining 9 items. Factor analysis now produced eigenvalues between 3.97 and .40 , with one eigenvalue $(3.97)>1$. The one factor explained $44.1 \%$ of the total variance. All nine items loaded $>.30$ on this factor with loadings varying between .45 and .77 . Eight of the 9 items loaded $>$ .50 on this factor. The factor loadings are shown in Table 1

Table 1 Factor loadings of items in Kanungo's Job Involvement Questionnaire in one factor solution

\begin{tabular}{|c|c|}
\hline $\begin{array}{c}\text { Job Involvement Items } \\
\text { (Numbers as in JIQ) }\end{array}$ & Factor Loadings \\
\hline 8 & 0.773 \\
9 & 0.764 \\
4 & 0.741 \\
5 & 0.741 \\
1 & 0.663 \\
10 & 0.651 \\
6 & 0.561 \\
3 & 0.559 \\
2 & 0.447 \\
\hline
\end{tabular}

Item analyses resulted in all the items having a rn-value $>.30$, as shown in Table 2. 
Table 2 Corrected item weights of items in Kanungo's Job Involvement Questionnaire

\begin{tabular}{|c|c|}
\hline $\begin{array}{c}\text { Job Involvement Items } \\
\text { (Numbers as in JIQ) }\end{array}$ & rt-values \\
\hline 9 & 0.663 \\
8 & 0.662 \\
5 & 0.623 \\
4 & 0.627 \\
1 & 0.552 \\
10 & 0.530 \\
3 & 0.448 \\
6 & 0.452 \\
2 & 0.347 \\
\hline
\end{tabular}

Cronbach's Coefficient alpha was calculated on the items in the unidimensional instrument and resulted in a value of .83 . Confirmatory Factor Analysis was then carried out on the one-factor solution. The results are shown in Table 3.

The results of the analyses carried out on the responses to the Job Involvement Questionnaire seem to indicate that the measure is a robust, probably unidimensional scale. The Confirmatory Factor Analysis results seem to show that a one-factor solution provides quite a good fit. The construct seems to be quite portable between the USA and South Africa. The Job Involvement Questionnaire can probably be used with a great deal of confidence in South Africa.

The sample of 1791 professional people also completed the Minnesota Job Satisfaction Questionnaire. The responses were analyzed in a similar fashion to that of the JIQ. The Principal Components analysis with Promax rotation yielded three eigenvalues $>1.00$ (respectively $7.25 ; 1.62$ and 1.17 ). This again raised the possibility that the instrument could be unidimensional. A one-factor solution was therefore firstly specified. This yielded a factor on which all of the 20 items loaded $>.30$. The loadings varied between .40 and .74 . ltem analysis yielded corrected $\mathrm{r}_{\mathrm{u}}$-values ranging between .36 and .67 . It therefore seemed as if the items could all belong to one scale, of which the Cronbach Alpha coefficient was 90 . This factor contained $36.3 \%$ of the total variance. 
Table 3 Indices obtained from Confirmatory Factor Analysis on one factor solution (Kanungo's Job Involvement Inventory)

\begin{tabular}{|l|c|}
\hline Fit indices & Value \\
\hline Goodness of Fit Index (GFI) & .9685 \\
\hline GFI Adjusted for df (AGFI) & .9455 \\
\hline Root Mean Square Residual & .0359 \\
\hline Chi-square df=26 p=.0001 & 227.8937 \\
\hline Null-model Chi-square df =36 & 4648.8185 \\
\hline Diff Chi-square (df =10) & 4420.9248 \\
\hline Akaike's Information Criterion & 178.14 \\
\hline Bozdogan's (1987) CAIC & 7.5792 \\
\hline Bentler \& Bonnett's (1980) Non-Normed Index & .9394 \\
\hline Bentler \& Bonnett's (1980) NFI & .9510 \\
\hline Relative Non-centrality Index (RNI) & .9562 \\
\hline Bollen (1986) Normed Index Rho1 & .9322 \\
\hline Bollen (1988) Non-Normed Index Delta2 & .9563 \\
\hline
\end{tabular}

A three factor solution with Promax rotation was also specified - in the light of three eigenvalues being $>1.00$. In this solution eight items had their highest loadings on factor one. Six items had their highest loadings on, respectively, factors two and three. All these loadings were above .40. A three factor solution yielded factors which were quite highly intercorrelated with each other (between .38 and .49 ). Factor two correlated with respectively factors one and three .49 and .46. Factors one and three correlated .38 with each other after the Promax rotation. Cross loadings were evident in the factor pattern. All the items with highest loadings on a factor also had at least one loading $>.30$ on another factor. Item analyses were subsequently carried out on the items with their highest loadings on each factor. All the items included in each of the three factors (according to the Principal components analysis) had corrected ru-values of $>.30$, varying between .37 and .73 . After Promax rotation the three factors respectively explained $36.3 \%, 8.1 \%$ and $5.9 \%$ of the total variance. 
Specifying a two-factor solution with Promax rotation yielded two factors which after rotarion correlated .54 with each other and respectively explained $52.8 \%$ and $47.2 \%$ of the common variance. Twelve items had their highest loadings on factor one. These loadings varied between .39 and .78 . The eight items loading highest on factor two had loadings on this factor of between .64 and .78 . Item analyses yielded ru-values of between .34 and .68. Cronbach's Alpha for factor one was .87 and for factor two .84 . Factor one explained $36.3 \%$ and factor two $8.1 \%$ of the total variance. The two factors together explained $44.4 \%$ of the total variance. After Promax rotation all the items had loadings of at least .30 on both factors.

To determine which of the solutions provided the best 'fit', Confirmatory Factor Analysis were carried out on the factor patterns for one, two and three factor solutions. The indices are compared in Table 4. 
Table 4 Results of Confirmatory Factor Analysis on one, two and threefactor solutions of responses in MSQ

\begin{tabular}{|l|c|c|c|}
\hline \multicolumn{1}{|c|}{ Fit indices } & $\begin{array}{c}\text { One } \\
\text { factor }\end{array}$ & $\begin{array}{c}\text { Two } \\
\text { factors }\end{array}$ & $\begin{array}{c}\text { Three } \\
\text { factors }\end{array}$ \\
\hline Goodness of Fit Index (GF) & .8260 & .8799 & .8918 \\
\hline GFI Adjusted for df (AGFD & .7838 & .8799 & .8639 \\
\hline Root Mean Square Residual & .0652 & .0529 & .0514 \\
\hline Chi-square (df) & 3167.845 & 2276.384 & 2055.436 \\
& $(169)$ & $(168)$ & $(167)$ \\
\hline Null model Chi-square df=190 & 13430.16 & 13430.16 & 13430.16 \\
\hline Diff Chi-square (df) & $(190)$ & $(190)$ & $(190)$ \\
\hline Bentler's Comparative Fit Index & 12062.32 & 11153.78 & 11374.73 \\
\hline Akaike's Information Criterion & 2829.845 & 1940.384 & 1721.436 \\
\hline Bozdogan's (1987) CAIC & 1735.8006 & 852.8138 & 640.3393 \\
\hline Bentler \& Bonnett's (1980) Non- & .7454 & .8199 & .8377 \\
\hline Normed Index & & & $(32)$ \\
\hline Bentler \& Bonnett's (1980) NFI & .7641 & .8305 & .8470 \\
\hline Relative Non-centrality Index (RND) & .7735 & .8408 & .8574 \\
\hline Bollen (1986) Normed Index Rhol & .7348 & .8083 & .8259 \\
\hline Bollen (1988) Non-Normed Index & .7734 & .8410 & .8576 \\
Delta2 & & .8408 & .8574 \\
\hline
\end{tabular}

The two- and three-factor solutions both seemed to provide a better fit than the one factor solution, but also had highly intercorrelated factors as explained before. The second factor (in a two factor solution) and the second and third factors (in the three factor solution) explained relatively small percentages of the total variance. 
The one-factor solution on the other hand yielded a relatively good fit with most of the indices reaching acceptable levels. To use the instrument as a unidimensional measure will probably be acceptable. The factor loadings and the item weights (corrected ru-values) are shown in Table 5.

Table 5 Factor loadings and corrected $r_{a}$ values of items in MSQ (One factor solution)

\begin{tabular}{|c|c|c|}
\hline Item (no in MSQ) & Factor loading & Corrected ru value \\
\hline 1 & .553 & .491 \\
2 & .536 & .469 \\
3 & .604 & .536 \\
4 & .610 & .549 \\
5 & .578 & .529 \\
6 & .593 & .546 \\
7 & .559 & .498 \\
8 & .403 & .361 \\
9 & .503 & .442 \\
10 & .474 & .422 \\
11 & .698 & .630 \\
12 & .659 & .608 \\
13 & .504 & .458 \\
14 & .651 & .599 \\
15 & .738 & .672 \\
16 & .718 & .648 \\
17 & .653 & .602 \\
18 & .500 & .450 \\
19 & .647 & .593 \\
20 & .717 & .653 \\
\hline
\end{tabular}

From Table 5 it can be seen that all the items had acceptable item weights and factor loadings, making for a robust scale.

The one factor solution on the MSQ responses was investigated further. Bagozzi \& Heatherton (1994) state that the "fit" indicated by the indices yielded by 
Confirmatory Factor Analysis can be an underestimation of the quality of the fit when the scales included in the analysis consists of several items. The same is true when large samples are used. In the present study quite a large sample $(N=1791)$ was involved and the one-factor solution on the items of the MSQ contained 20 items. A procedure advocated by Bagozzi \& Heatherton (1994) was therefore carried out. This consisted of forming aggregate "items" by combining groups of items in the MSQ with each other. In this way the following aggregates were formed: Items $1-4 ; 5-8 ; 9-12 ; 13-36$ and $17-20$. The aggregates were then used as variables in a second order Principal Components Analysis.

The factor pattern obtained from a Principal Components Analysis with one factor specified indicated factor loadings for the different aggregates of $.84, .84$, $.83, .80$ and .79 . A Confirmatory Factor Analysis yielded the indices as shown in Table 6.

Table 6 Results of CFA on Msq Factor Pattern (Secondary Analysis)

\begin{tabular}{|l|r|}
\hline Goodness of fit Index (G.F.I.) & .9836 \\
\hline $\begin{array}{l}\text { GFI Adjusted for Degrees of Freedom } \\
\text { (AGFI) }\end{array}$ & .9384 \\
\hline Root Mean Square Residual (RMR) & .0217 \\
\hline Relative Non-centrality Index (RNI) & .9836 \\
\hline Bentler's Comparative Fit Index & .9836 \\
\hline Akaike's Information Criterion & 65.1881 \\
\hline Bozdogan's (1987) CAlC & 39.2935 \\
\hline $\begin{array}{l}\text { Bentler \& Bonnett's (1980) Non-normed } \\
\text { Index }\end{array}$ & .9590 \\
\hline Bentler \& Bonnett's (1990) NFI & .9827 \\
\hline Bollen (1986) Normed Index Rhol & .9567 \\
\hline Bollen (1988) Non-normed Index Delta2 & .9836 \\
\hline Chi-square df =4 p=.0001 & 73.1881 \\
\hline Null Model Chi-square df $=10$ & 4225.2171 \\
\hline Diff Chi-square df =6 p=.0001 & 4152.0290 \\
\hline
\end{tabular}


From Table 6 it can be seen that elimination of error variance resulted in a very good fit being obtained. A one-factor structure can therefore probably be accepted as representing the variance measured by the MSQ.

\section{DISCUSSION}

The results of the analyses of the characteristics of the JIQ seem to indicate that the construct is 'portable' to the South African situation, at least as represented by the samples on which the results reported in this paper were obtained.

The MSQ proved to be probably essentially one-dimensional. The scale seems to be robust when used on a sample from the South African population instead of that of the United States.

It should be clearly remembered that the respondents on whose responses the analyses presented in this paper were carried out were predominantly white, middle class and upper middle class South Africans. These samples probably did not differ much from the validation samples used by the authors of the two instruments. The question therefore remains: Will these results stand up to crossvalidation on black, Asian and South African mixed race samples? Put differently the question is: Are the constructs job satisfaction and job involvement the same for different ethnic/cultural and different socio-economic groups? It seems as if a rich possibility for further research exists in this regard.

\section{REFERENCES}

1. BAGOZZI, R.P. \& HEATHERTON, T.F. (1994). A general approach to representing multifaceted personality constructs: application to self-esteem. Structural Equation Modelling, 1, 35-67.

2. BOSHOFF, A.B., BENNETT, H.F. \& KELLERMAN, A.M. (1994). Prediction of job involvement of professionals by means of career orientations scores. Journal of Industrial Psychology, 20(2), 8 - 13.

3. BOSHOFF, A.B., KAPLAN, R.A.L., SCHUTTE, J.L. \& KELLERMAN, A.M. (1989). Job satisfaction, job involvement and career anchors of professionals in a Third world / First world country. Proceedings of the Second International Conference on Comparative Management. Kaohsiung, Taiwan, $80-112$.

4. KANUNGO, R.N. (1982). Measurement of job and work involvement. Journal of Applied Psychology, 67(3), 341 - 349. 
5. KERLINGER, F.N. (1986). Foundations of Behavioral research. New York, Holt, Rinehart \& Winston.

6. LODAHL, T.M. \& KEJNER, M. (1965). The definition and measurement of job involvement. Journal of Applied Psychology, 49(1), 24 - 33.

7. ROBINSON, P.B., STIMPSON, D.V., HUEFNER, J.C. \& HUNT, H.K. (1991). An attitude approach to the prediction of entrepreneurship. Entrepreneurship Theory and Practice, 15(4) 13 - 30.

8. STIMPSON, D.V., ROBINSON, P.B., WARONUSUNTIKULE, S. \& ZHENG, R. (1990). Atritudinal characteristics of entrepreneurs in the United States, Korea, Thailand and the Peoples Republic of China. Entrepreneurship and Regional Development, 2, 49 - 55.

9. STIMPSON, D.V., HUEFNER, J.C., NARAYANAN, S. \& SHANTHAKUMAR, D. (1992). Atritudinal characteristics of male and female entrepreneurs in the United States and India. Paper read at 2 nd Conference on internationalizing entrepreneurship research, education and training. Dormund, June.

10. WEISS, D.J., DAWIS, R.V., ENGLAND, G.W. \& LOFQUIST, L.H. (1967). Manual for the Minnesota Satisfaction Questionnaire. Minneapolis, University of Minnesota. 